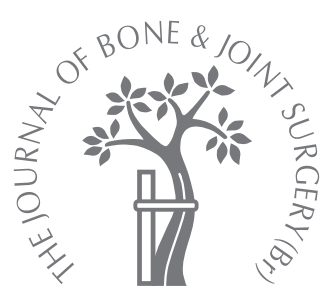

Y. Hara,

N. Ochiai,

I. Abe,

H. Ichimura,

Saijilafu,

Y. Nishiura

From University of Tsukuba, Ibaraki, Japan

Y. Hara, MD, PhD, Assistant

N. Ochiai, MD, PhD,

Professor

- Saijilafu, MD, Student

Y. Nishiura, MD, PhD,

Assistant Professor

Department of Orthopaedic

Surgery

Graduate School of

Comprehensive Human

Sciences, University of

Tsukuba, 1-1-1 Tennoudai,

Tsukuba-shi, Ibaraki 305-8575,

Japan.

I. Abe, MD, PhD, Assistant

Professor

Department of Orthopaedic

Surgery

Ibaraki Profectural University of

Health Sciences, 4669-2, Ami,

Amimachi, Inashiki, Ibaraki 300

0394, Japan.

- H. Ichimura, FRCS, MD, PhD, Orthopaedic Surgeon

Department of Orthopaedic

Surgery

Showa General Hospital, 2-450, Tenjin, Kodaira, Tokyo, Ibaraki 187-8510, Japan.

Correspondence should be sent to Dr Y. Hara; e-mail:

yukihara@mail1.accsnet.ne.jp

(C2007 British Editorial Society of Bone and Joint Surgery doi:10.1302/0301-620X.89B6. $18569 \$ 2.00$

$J$ Bone Joint Surg $[\mathrm{Br}]$ 2007;89-B:830-5.

Received 24 August 2006;

Accepted after revision 17

January 2007

\title{
Effect of progesterone on recovery from nerve injury during leg lengthening in rats
}

\begin{abstract}
We investigated the effect of progesterone on the nerve during lengthening of the limb in rats. The sciatic nerves of rats were elongated by leg lengthening for ten days at $3 \mathrm{~mm}$ per day. On alternate days between the day after the operation and nerve dissection, the progesterone-treated group received subcutaneous injections of $1 \mathrm{mg}$ progesterone in sesame oil and the control group received oil only. On the fifth, tenth and 17th day, the sciatic nerves were excised at the midpoint of the femur and the mRNA expression level of myelin protein $\mathrm{PO}$ was analysed by quantitative real time polymerase chain reaction. On day 52 nodal length was examined by electron microscopy, followed by an examination of the compound muscle action potential (C-MAP) amplitude and the motor conduction velocity (MCV) of the tibial nerve on days 17 and 52. The P0 (a major myelin glycoprotein) mRNA expression level in the progesterone-treated group increased by $46.6 \%$ and $38.7 \%$ on days five and ten, respectively. On day 52 , the nodal length in the progesterone-treated group was smaller than that in the control group, and the MCV of the progesterone-treated
\end{abstract} group had been restored to normal.

Progesterone might accelerate the restoration of demyelination caused by nerve elongation by activating myelin synthesis.

Lengthening of limbs is frequently employed to treat discrepancy in length. Although lengthening techniques have improved, complications of the peripheral nerves are still occasionally reported. Patients may suffer from pain, dysaesthesia or hyperaesthesia and, in more serious cases, permanent motor palsy and sensory loss. Paley ${ }^{1}$ reported four cases of motor palsy in 60 limbs which were subjected to lengthening by the Ilizarov technique. ${ }^{2}$ The frequency of nerve injury was high in lower limb lengthening in achondroplastic patients. ${ }^{3,4}$ The elongated nerve has been reported to show demyelination or axonal degeneration which correlates with the distance and/or speed of lengthening. The lengthened nerve also shows electrophysiological abnormalities resulting from mechanical injury and ischaemia. ${ }^{5-7}$ We have investigated the morphological changes in peripheral nerves in femoral lengthening in adult rats. Almost all sciatic nerve fibres showed paranodal demyelination at a lengthening speed of $3 \mathrm{~mm}$ per day. ${ }^{8-11}$ We have also reported that the peripheral nerve recovers from paranodal demyelination by synthesising myelin sheath, resulting in increases in internodal length. ${ }^{8,9}$ We hypothesised that injury of the peripheral nerve can be prevented during limb lengthening by activating myelin synthesis.
It has been shown that steroid sex hormones regulate important functions in neuronal development and regeneration, thus giving them the name 'neurosteroids'. ${ }^{12-15}$ Previous investigations have shown that progesterone, pregnenolone and their reduced or sulphated metabolites promote synthesis of myelin in peripheral nerves. ${ }^{16-18}$ Therefore, we predicted that progesterone will aid recovery of the peripheral nerve.

In order to test our hypothesis, we quantified P0 (myelin protein zero) mRNA. This allowed us to determine whether progesterone activates the synthesis of myelin in rat models of femoral lengthening. The myelin-specific protein $\mathrm{P} 0$, a major structural protein that constitutes more than $50 \%$ of proteins present in the peripheral myelin sheath, ${ }^{19}$ has been used as a marker of myelination. ${ }^{20-22}$ Through histological and electrophysiological studies we investigated whether progesterone exerts any effect on an elongated nerve.

\section{Materials and Methods}

A total of 50 male Wistar rats aged 13 weeks and weighing between $380 \mathrm{~g}$ and $430 \mathrm{~g}$ were maintained according to the guidelines of the Ethics Committee of the University of Tsukuba. 
Surgical procedure. Under anaesthesia induced by intraperitoneal sodium pentobarbital $(40 \mathrm{mg}$ per $\mathrm{kg}$ bodyweight), the right femur was exposed and osteotomised at its mid-point. An external fixator was applied across the gap and the wound closed. Over the course of ten days, beginning from the day after the operation, the sciatic nerve was elongated indirectly by lengthening the femur at a rate of $3 \mathrm{~mm}$ per day. Sodium pentobarbital $(20 \mathrm{mg}$ per $\mathrm{kg}$ body-weight) was injected at each adjustment of the fixator. The pin sites were redressed daily. Femoral lengthening of $30 \mathrm{~mm}$ was maintained until nerve dissection.

Medication. The rats were divided randomly, using the toss of a coin, into two groups. From the day after the operation until nerve dissection, the progesterone-treated group received subcutaneous injections of $1 \mathrm{mg}$ progesterone suspended in $250 \mu \mathrm{l}$ sesame oil on alternate days. The control group received subcutaneous injections of $250 \mu \mathrm{l}$ of sesame oil.

Morphological analyses. At day 52 after the initiation of nerve lengthening, five rats in each group were killed with an overdose of sodium pentobarbital and the left ventricle was perfused with $3 \%$ glutaraldehyde and 3\% paraformaldehyde in $0.1 \mathrm{M}$ cacodylate buffer ( $\mathrm{pH} 7.4)$. The sciatic nerves were excised at the mid-point of the femur. These specimens were immersed in the above buffered fixative for one hour, post-fixed in $2 \%$ osmium tetroxide for three hours, dehydrated in a graded ethanol series, and embedded in Epon 812 (TAAB Laboratories Equipment Ltd, Aldermaston, United Kingdom). Semi-thin transverse sections $(1 \mu \mathrm{m}$ thick) were cut and stained with toluidine blue for light microscopy observations. Longitudinal ultra-thin sections (70 nm to $80 \mathrm{~nm}$ thick) were mounted on copper grids. After staining with lead citrate and uranyl acetate, the sections were observed under an electron microscope (H7000; Hitachi, Tokyo, Japan); 50 nodes of Ranvier were examined for each animal, and the nodal length was measured.

RNA extraction and reverse transcription. At five, ten and 17 days after the initiation of nerve lengthening, five rats from each group were killed with an overdose of sodium pentobarbital and both sciatic nerves were similarly excised. The total RNA was isolated and purified from 30 mg of each sample using an RNeasy Protect Mini kit (Qiagen, Hilden, Germany), as described previously. ${ }^{9}$ The reaction products were stored at $-20^{\circ} \mathrm{C}$ until further PCR analysis.

Quantitative RT-PCR analysis. The quantity of mRNA was determined using a PRISM 7700 sequence detection system (Applied Biosystems, Foster City, California) with TaqMan standard curve methods ${ }^{23}$ with a two-step PCR protocol at $95^{\circ} \mathrm{C}$ for ten minutes, followed by 40 cycles of $95^{\circ} \mathrm{C}$ for 15 seconds and $60^{\circ} \mathrm{C}$ for one minute, as described previously. ${ }^{11}$ TaqMan probes for rat P0 were as follows: forward primer, 5'-TCTTTTACCTGGCGCTACCAG-3'; reverse primer, 5'GTTGACCCTTGGCATAGTGGA-3'; and TaqMan probe, 5'-Fam-AAGGAGGCCGAGATGCCATTTCAATC Tamra-
3', which amplified a $73 \mathrm{bp}$ region of rat P0 mRNA (nucleotides 218 to 290; NCBI accession no. K03242). To account for the variation in quality of mRNA between samples, glyceraldehyde-3-phosphate dehydrogenase (GAPDH) was analysed as an internal control. The primers and TaqMan probe for GAPDH were produced by Applied Biosystems (TaqMan Rodent GAPDH Control Reagents, VIC Probe).

Electrophysiology. At 17 and 52 days after the initiation of lengthening, the motor conduction velocity (MCV) and the compound muscle action potential (C-MAP) amplitude were used to assess neural function. The five rats from each group were laid on a hot plate and their rectal temperature was monitored. The nerve was stimulated at the ischial tuberosity and at the entrance of the extensor digitorum longus muscle of the tibial nerve. The recording was carried out at the gastrocnemius muscle. The stimulus used consisted of a square-wave pulse of $0.1 \mathrm{~ms}$ duration delivered by an isolator at an amplitude that was adjusted to that of the supramaximal stimulus. C-MAP was amplified, digitised, recorded, and analysed using a computer with MacLab (ADInstruments, Castle Hill, New South Wales, Australia). C-MAP amplitude was quantified by its peakto-peak amplitudes in the tibial nerve. The conduction velocity was assessed in combination with the interelectrode distance and negative peak latency.

Statistical analysis. All data are presented as the mean \pm SD. Two-factorial ANOVA ${ }^{24}$ and Fisher's PLSD $^{24}$ were used to evaluate differences in the relative quantities of mRNA, MCV and C-MAP between the progesterone-treated group and the control group. Student's $t$-test for unpaired data was used to evaluate differences in nodal length between the two groups. A p-value $<0.05$ was considered to indicate statistical significance.

\section{Results}

Morphological analyses. Light microscopic observations of transverse sections at 52 days after the initiation of lengthening showed no significant differences in either axon diameter or thickness of the myelin sheath between the two groups (Fig. 1). There was no myelin debris or endoneurial oedema in either group. The electron microscopic analysis of longitudinal sections on day 52 showed that the mean nodal lengths were $5.43 \mu \mathrm{m}$ in the progesterone-treated group and $6.29 \mu \mathrm{m}$ in the control group. Almost all fibres in both groups showed nodal lengths of $1 \mu \mathrm{m}$ to $5 \mu \mathrm{m}$ (Fig. $2 \mathrm{a}$ ), but some had nodal lengths of more than $10 \mu \mathrm{m}$ (Fig. $2 \mathrm{~b})$, which indicates demyelination. The percentages of fibres with nodal lengths of more than $10 \mu \mathrm{m}$ were $7.14 \%$ (SD $1.35 \%$ ) in the progesterone-treated group and $14.29 \%$ (SD $3.18 \%$ ) in the control group. The number of fibres with a long nodal length in the progesterone-treated group was significantly lower than in the control group ( $\mathrm{p}=0.045)$.

Quantitative analysis of P0 mRNA. In order to examine the effects of progesterone on the myelin synthesis of elongated nerves, we analysed the changes in the level of mRNA 


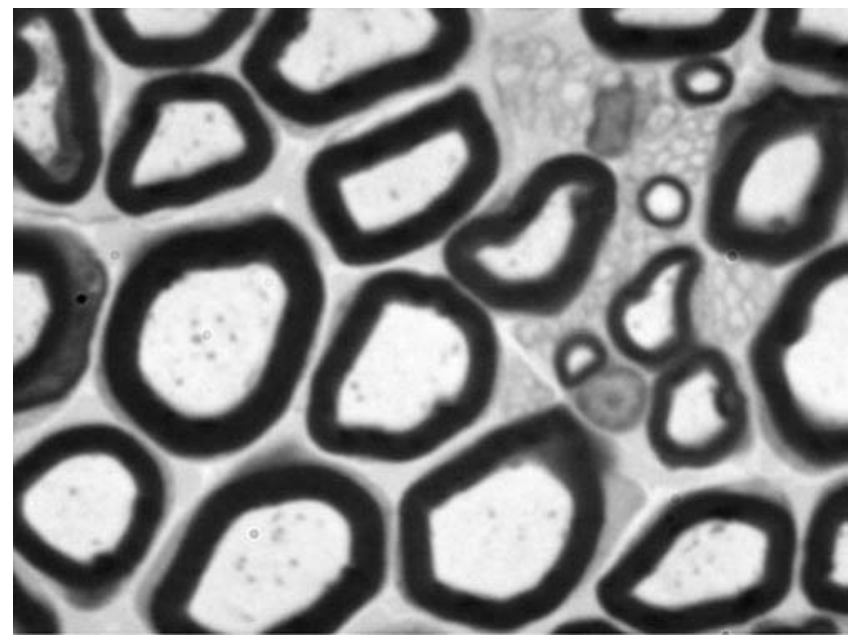

Fig. 1a

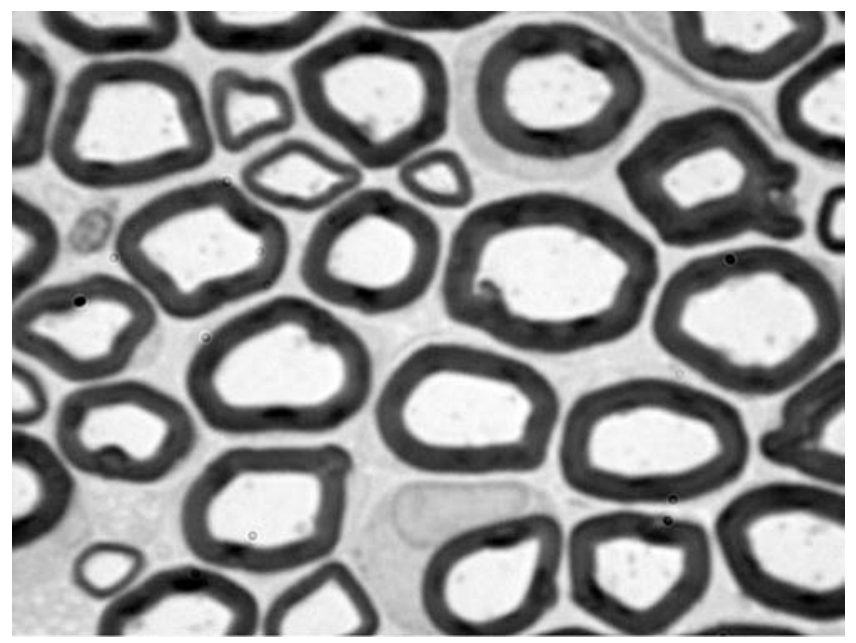

Fig. 1b

Transverse sections of sciatic nerves on day 52 observed by light microscopy a) progesterone-treated group and b) control group. No significant differences were evident in either axon diameter or thickness of myelin sheath between the two groups. Scale bars: $10 \mu \mathrm{m}$.

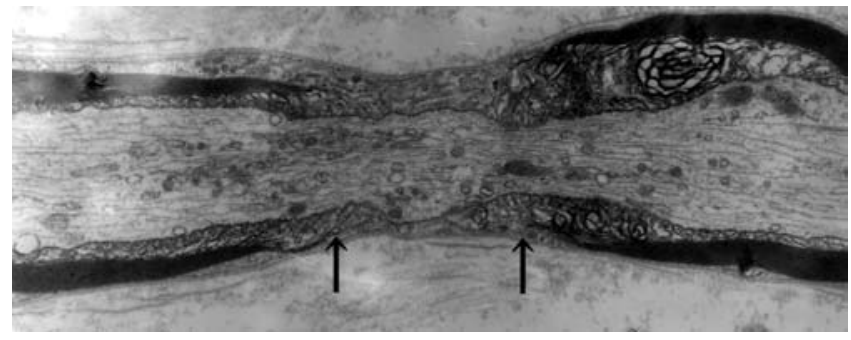

Fig. 2a

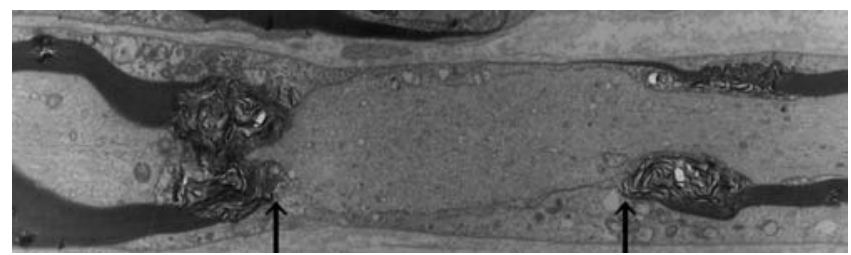

Fig. $2 b$

expression of $\mathrm{P} 0$, a major myelin glycoprotein, by quantitative RT-PCR analysis. GAPDH mRNA was used as the internal control; no significant differences in GAPDH mRNA expression level were observed between the two groups at any time. We calculated the relative quantities of P0 mRNA by dividing the values of P0 mRNA by that of GAPDH mRNA. No significant difference in the relative quantity of P0 mRNA were noted in the control group at any time during the experiment.

Five days after the initiation of lengthening, the relative quantity of P0 mRNA in the progesterone-treated group was 35.64 (SD 7.54), and that in the control group was 24.31 (SD 8.74). The level of expression of P0 mRNA in the progesterone-treated group increased significantly by
Longitudinal sections of sciatic nerves on day 52 observed by electron microscopy. Nodal lengths (the distance between the arrow heads) of almost all the fibres were between $1 \mu \mathrm{m}$ to $5 \mu \mathrm{m}$ in both groups. Figure 2a shows a fibre with a nodal length of $2.27 \mu \mathrm{m}$ in the progesteronetreated group. There were twice as many fibres with nodal lengths of more than $10 \mu \mathrm{m}$ in the control group as in the progesterone-treated group; figure $2 \mathrm{~b}, 13.3 \mu \mathrm{m}$.
$46.6 \%$ compared with the control group $(0 \%, p=0.048$; Fig. 3). On day ten, the relative quantity of P0 mRNA was 37.55 (SD 9.27) in the progesterone-treated group and 27.07 (SD 9.62) in the control group. There was no significant difference, although P0 mRNA expression in the progesterone-treated group increased by $38.7 \%$. P0 mRNA expression in the progesterone-treated group increased transiently between day five and day 17 . At 17 days the level of expression in the control group increased, but there was no significant difference between the two groups.

Electrophysiology. At day 17 after the initiation of lengthening, the mean MCV of both groups decreased, $15.40 \mathrm{~m} / \mathrm{s}$ (SD 5.3) in the progesterone-treated group and $20.25 \mathrm{~m} / \mathrm{s}$ 
(SD 11.9) in the control group. At 52 days, the mean MCV of the progesterone-treated group increased to $34.93 \mathrm{~m} / \mathrm{s}$ (SD 8.6), but that of the control group was $15.98 \mathrm{~m} / \mathrm{s}(\mathrm{SD}$ 6.0). A significant difference was observed between the two groups at 52 days ( $\mathrm{p}=0.016$; Fig. $4 \mathrm{a})$. The mean C-MAP amplitude in the progesterone-treated group was $11.0 \mathrm{mv}$ (SD 2.09) on day 17, and $15.8 \mathrm{mv}$ (SD 1.42) on day 54, and that in the control group was $6.76 \mathrm{mv}$ (SD 1.10) on day 17 and $8.77 \mathrm{mv}$ (SD 1.03) on day 54. At both time points, the amplitude of C-MAP in the progesterone-treated group was higher than in the control group, with significant differences (Fig. 4b).

\section{Discussion}

The level of expression of P0 mRNA in the progesteronetreated group increased significantly on day five, whereas in the control group it had only begun to increase on day 17 . Remyelination in an elongated nerve might have started earlier in theprogesterone-treated group, resulting from the promotion of myelin synthesis by progesterone. There is evidence that progesterone accelerates myelin formation in rat Schwann cell neuron co-culture. ${ }^{12}$ The nodal length of the progesterone-treated group was smaller than in the control group on day 52. In our previous study, we observed teased fibres of rat sciatic nerve. In normal nerve, less than $5 \%$ of fibres have shown paranodal demyelination. ${ }^{8}$ In this study, the proportion of fibres with a large nodal length was about $7 \%$ in the progesterone-treated group and $14 \%$ in the control group. The incidence of demyelination in the progesterone-treated group was half of that in the control

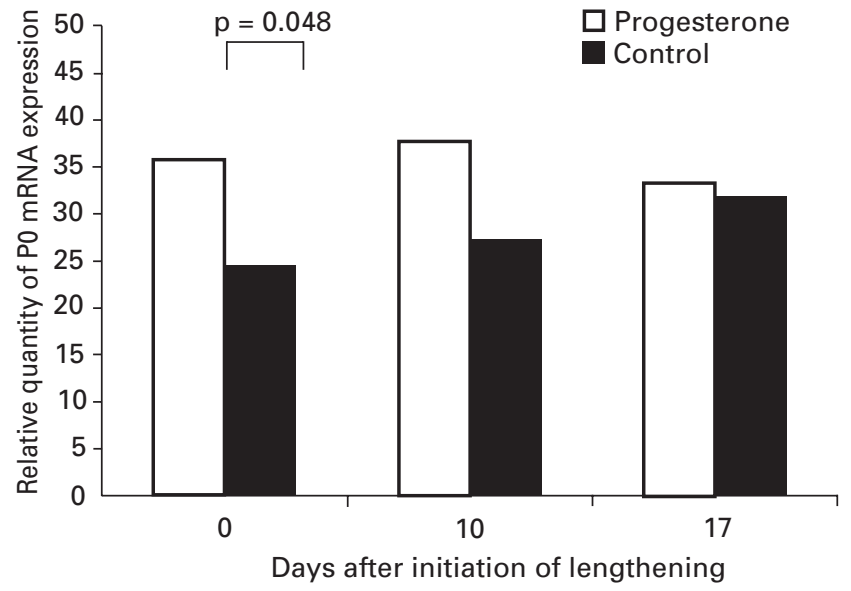

Fig. 3

Bar chart showing changes in P0 mRNA expression level with time, determined by quantitative RT-PCR analysis. On day five, the relative quantity of PO mRNA in the progesterone-treated group was 35.64 (SD 7.54 ), and that in the control group was 24.31 (SD 8.74). P0 mRNA expression level in the progesterone group increased with significant difference $(p=0.048)$. In the progesterone-treated group it was increased transiently to 17 days. On day 17, P0 mRNA expression level in the control group increased, but there was no significant difference between the two groups.

group. This suggests that the progesterone-treated group made a good recovery from the demyelination caused by nerve elongation. Furthermore, the amplitude of C-MAP of the progesterone-treated group was higher than in the con-

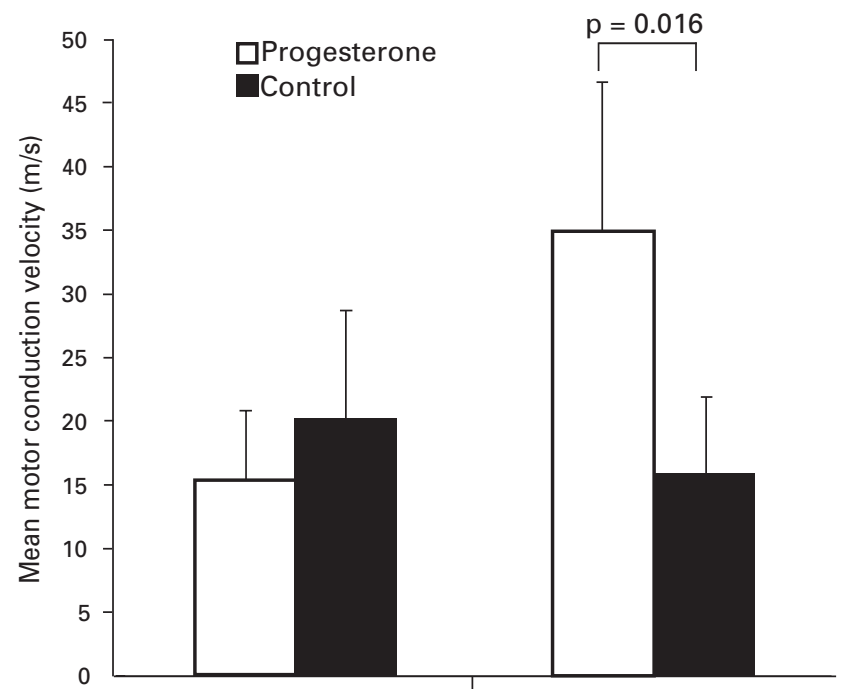

17

52

Days after initiation of lengthening

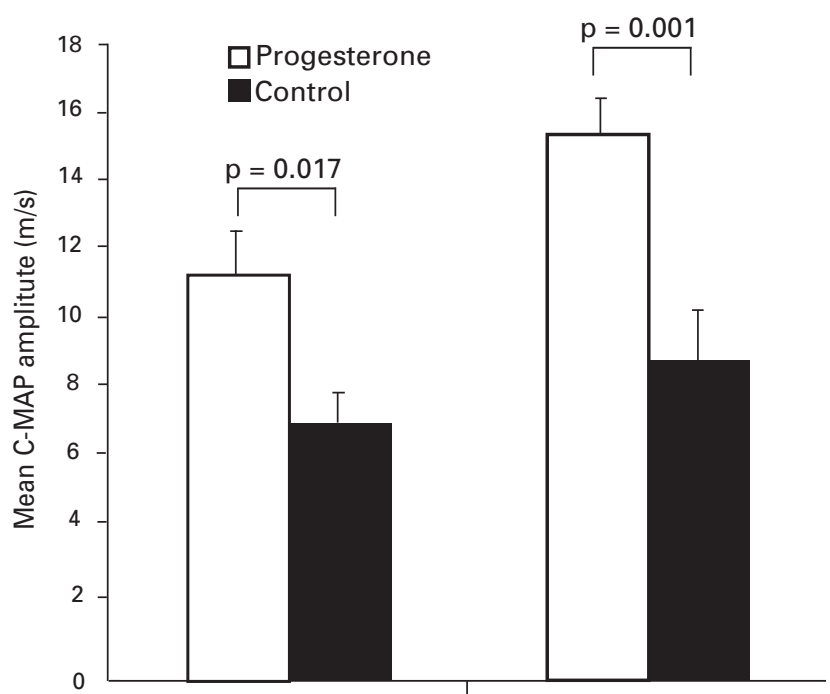

17

Days after initiation of lengthening

Fig. 4b

a) On day 17, the mean motor conduction velocity (MCV) of both groups was decreased: $15.40 \mathrm{~m} / \mathrm{s}$ (SD 5.3 ) in the progesterone-treated group and $20.25 \mathrm{~m} / \mathrm{s}$ (SD 11.9) in the control group. On day 52, the mean MCV of the progesterone-treated group increased to $34.93 \mathrm{~m} / \mathrm{s}$ (SD 8.6 ), but that of the control group was $15.98 \mathrm{~m} / \mathrm{s}$ (SD 6.0). A significant difference was observed between the two groups on day $52(p=0.016)$. b) Mean compound muscle action potential (C-MAP) amplitudes in the progesterone-treated group were higher than in the control group on days 17 and 54 , with statistically significant differences. 
trol group on days 17 and 54, and the MCV of the progesterone-treated group was faster on day 52 . This indicates that functional recovery in this group was better than in the control group. These results suggest that progesterone might accelerate the rescue of electrophysiological abnormalities caused by nerve stretching.

The pathological change caused by a gradual elongation of a nerve is generally demyelination. ${ }^{5,6,8}$ In recent studies, we have demonstrated that peripheral nerves can initially recover from demyelination by synthesis of myelin during gradual elongation under appropriate conditions. ${ }^{8-10}$ Interactions between axons and Schwann cells are important for myelin formation, ${ }^{25}$ and the initiation of myelination and the thickness of the myelin sheath are regulated by specific properties of axons. ${ }^{26}$ Elongation of a nerve may cause some changes in both nodal structure and the lamellar form of the myelin sheath created by slippage in the localisation of the node or the increase in nodal length. These changes may affect components of the axonal and extracellular matrix and stimulate myelin synthesis in Schwann cells. There probably is a limit to the capacity of restoration of demyelination. Thus disorders of a peripheral nerve may occur when the speed of lengthening or distance are excessive. However, it might be possible to prevent these disorders by promoting myelin synthesis, as shown in this study.

Several neurotrophic factors, such as insulin-like growth factors, ${ }^{27}$ neurotrophin (NT)-3, ${ }^{28}$ and brain-derived neurotrophic factor (BDNF), ${ }^{28,29}$ as well as neurosteroids, are regulators of myelination. Among them, progesterone is already in therapeutic use in the field of obstetrics. Although side effects, including pseudopregnancy symptoms such as nausea or transient fever occasionally occur, the safety of this therapy is established. In recent studies, several effects of progesterone on the nervous system were observed and the molecular mechanisms underlying these effects have been investigated. Progesterone is locally synthesised by Schwann cells. ${ }^{16}$ They also have an intracellular receptor for progesterone, which functions as an autocrine signalling molecule. ${ }^{30}$ Progesterone may promote myelination at the transcriptional level by activating the expression of genes coding for the transcription factors (Krox-20) of myelin proteins. ${ }^{31}$ It has been reported that progesterone promotes myelination in regenerating nerves or cultures of Schwann cells. ${ }^{11,29,32,33}$ Progesterone also rescues segmental demyelination induced by ageing by stimulating $\mathrm{P} 0$ gene expression. ${ }^{16}$ In addition, progesterone promotes the proliferation of Schwann cells and neural progenitor cells. ${ }^{14,17}$ These studies have shown the many actions of progesterone in the central and peripheral nervous systems.

In this study we have demonstrated that progesterone might have a recovery effect on the nerve injury which occurs during limb lengthening. This finding may have other important clinical implications. One is in the treatment of demyelinating polyneuropathies, such as the Guillain-Barré syndrome or diabetic neuropathy, and the other is in the repair of nerve gaps by gradual elongation of the nerve. ${ }^{34-36}$ The development of this therapy that can prevent the side effects of long-term medication might encourage the use of progesterone as a neurotherapeutic agent.

We thank Dr Takashi Shiga and members of the Shiga Laboratory for their excellent technical assistance.

No benefits in any form have been received or will be received from a commercial party related directly or indirctly to the subject of this article.

\section{References}

1. Paley D. Problems, obstacles, and complications of limb lengthening by the llizarov technique. Clin Orthop 1990;250:81-104

2. Ilizarov GA. The tension-stress effect on the genesis and growth of tissues. Part I: the influence of stability of fixation and soft-tissue preservation. Clin Orthop 1989;238:249-81.

3. Galardi G, Comi G, Lozza L, et al. Peripheral nerve damage during limb lengthening: neurophysiology in five cases of bilateral tibial lengthening. J Bone Joint Surg [Br] 1990;72-B:121-4.

4. Polo A, Aldegheri R, Zambito A. Lower-limb lengthening in short stature: an electrophysiological and clinical assessment of peripheral nerve function. J Bone Joint Surg [Br] 1997;79-B:1014-18.

5. Milner RH, Wilkins PR. The recovery of peripheral nerves following tissue expansion. J Hand Surg $[B r]$ 1992;17:78-85.

6. Van der Wey LP, Gabreëls-Fasten AA, Merks MH, et al. Peripheral nerve elongation by laser doppler flowmetry controlled expansion: morphological aspects. Acta Neuropath (Berl) 1995;89:166-71.

7. Abe Y, Doi K, Katoh Y, et al. The limit of low speed peripheral nerve elongation, neurological and circulatory aspects. J Neurol 1996;140:61-6.

8. Abe I, Tsujino A, Hara Y, Ichimura H, Ochiai N. Paranodal demyelination by gradual nerve stretch can be repaired by elongation of internodes. Acta Neuropathol (Berl) 2002;104:505-12.

9. Hara Y, Shiga T, Abe I, et al. P0 mRNA expression increases during gradual nerve elongation in adult rats. Exp Neurol 2003;184:428-35.

10. Abe I, Ochiai $\mathbf{N}$, Ichimura $\mathbf{H}$, et al. Internodes can nearly double in length with gradual elongation of the adult rat sciatic nerve. J Orthop Res 2004;22:571-7.

11. Ichimura H, Shiga T, Abe I, et al. Distribution of sodium channels during nerve elongation in rat peripheral nerve. J Orthop Sci 2005;10:214-20.

12. Chan JR, Phillips LJ 2nd, Glaser M. Glucocorticoids and progestines signal the initiation and enhance the rate of myelin formation. Proc Natl Acad Sci USA 1998;95:10459-64.

13. Magnaghi V, Cavaretta I, Galbiati M, Martini L, Melacangi RC. Neuroactive steroids and peripheral myelin proteins. Brain Res Rev 2001;37:360-71.

14. Huppenbauer CB, Tanzer L, DonCarlos LL, Jones KJ. Gonadal steroid attentuation of developing hamster facial motoneuron loss by axotomy: equal efficacy of tes tosterone, dihydrotestosterone, and 17-ßestradiol. J Neurosci 2005;25:4004-13.

15. Wang JM, Johnston PB, Ball BG, Brinton RD. The neurosteroid allopregnanolone promotes proliferation of rodent and human neural progenitor cells and regulates cell-cycle gene and protein expression. J Neurosci 2005;25:4706-18.

16. Koenig HL, Schumacher M, Ferzaz B, et al. Progesterone synthesis and myelin formation by Schwann cells. Science 1995;268:1500-3.

17. Melcangi RC, Magnaghi V, Cavarretta I, Martini L, Piva F. Age-induced decrease of glycoprotein $\mathrm{PO}$ and myelin basic protein gene expression in the rat sciatic nerve: repair by steroid derivatives. Neuroscience 1998;85:569-78.

18. Schmacher M, Guennoun R, Mercier G, et al. Progesterone synthesis and myelin formation in peripheral nerves. Brain Res Brain Res Rev 2001;37:343-59.

19. Greenfield S, Brostoff S, Eylar EH, Morell P. Protein composition of myelin of the peripheral nervous system. J Neurochem 1973;20:1207-16.

20. Poduslo JF. Regulation of myelination: biosynthesis of the major myelin glycoprotein by Schwann cells in the presence and absence of myelin assembly. J Neurochem 1984;42:493-503.

21. Lemke G, Axel R. Isolation and sequence of $c D N A$ encoding the major structural protein of peripheral myelin. Cell 1985;40:501-8.

22. Gupta SK, Poduslo JF, Mezei C. Temporal changes in PO and MBP gene expression after crush injury of the adult peripheral nerve. Molecular Brain Res 1988;4:133-41.

23. No authors listed. User Bulletin 2, Applied Biosystems, 1997. hhtp://docs.appliedbiosystems.com/pebiodocs/04303859 (date last accessed 30 May 2007).

24. Yanai H. Statcel - the useful addin forms on excel. Second ed. Japan: OMS Ltd, 2004

25. Mirsky R, Jessen KR. Schwann cell development, differentiation and myelination. Curr Opin Neurobiol 1996;6:89-96. 
26. Voyvodic JT. Target size regulates caliber and myelination of sympathetic axons Nature 1989;342:430-3.

27. Stewart HJS, Bradke F, Tabernero A, et al. Regulation of rat Schwann cell PO expression and DNA synthesis by insulin-like growth factors in vitro. Euro J Neurosci 1996;8:553-64.

28. Chan JR, Cosgaya JM, Wu YJ, Shooter EM. Neurotrophins are key mediators of the myelination program in the peripheral nervous system. Proc Natl Acad Sci USA 2001:98:14661-8

29. Zhang JY, Luo XG, Xian CJ, Liu ZH, Zhou XF. Endogenous BDNF is required for myelination and regeneration of injured sciatic nerve in rodents. Eur $J$ Neurosci 2000;12:4171-80.

30. Jung-Testas I, Schmacher M, Robel P, Baulieu EE. Demonstration of progesterone receptors in rat Schwann cells. J Steroid Biochem Kolec Biol 1996;58:77-82

31. Guennoun R, Benmessahel Y, Delespierre B, et al. Progesterone stimulates Krox-20 gene expression in Schwann cells. Mol Brain Res 2001;90:75-82.
32. Lacor $\mathbf{P}$, Gandolfo $\mathbf{P}$, Tonon MC, et al. Regulation of the expression of peripheral benzodiazepine receptors and their endogenous ligans during rat sciatic nerve degeneration and regeneration: a role for PBR in neurosteroidogenesis. Brain Res 1999;815:70-80.

33. Melcangi RC, Nagnaghi V, Galbiati M, et al. The action of steroid hormones on peripheral myelin proteins: a possible new tool for the rebuilding of myelin? J Neurocyto/ 2000;29:327-39.

34. Ohkaya S, Hirata H, Uchida A. Repair of nerve gap with elongation of Wallerian degenerated nerve by tissue expansion. Microsurgery 2000;20:126-30.

35. Krober MW, Diao E, Hida S, Liebenberg E. Peripheral nerve lengthening by controlled isolated distraction: a new animal model. J Orthop Res 2001;19:70-7.

36. Saijilafu, Nishiura Y, Yamada Y, et al. Experimental study for the repair of the peripheral nerve defect by direct, gradual distraction of the proximal nerve stump. Peripheral Nerve 2004;15:124-7 (in Japanese). 